\title{
Interaction of Phalloidin with Actin
}

\author{
(toxin/cyclic peptide/liver cell actin/cytochalasin B/microfilaments)
}

\section{ANNELIESE M. LENGSFELD*, IRMENTRAUT LÖW $\dagger$, THEODOR WIELAND $\dagger$, PETER DANCKER*, AND WILHELM HASSELBACH*}

* Departments of Physiologie and † Chemistry, Max-Planck-Institut fur Medizinische Forschung, Heidelberg, Germany

Communicated by F. Lynen, April 10, 1974

\begin{abstract}
Phalloidin, a toxic bicyclic peptide of rapid action from the toadstool, Amanita phalloides, gives rise to polymerization of G-actin to filamentous structures (Ph-actin) in a medium of low ionic strength. Ph-actin closely resembles the microfilaments found in liver membrane fractions (Ph-filaments) after in vivo or in vitro poisoning. Both phalloidin induced filaments are resistant to $0.6 \mathrm{M} \mathrm{KI}$ in contrast to F-actin, and become decorated by heavy meromyosin. After preincubation with cytochalasin B significantly fewer actin filaments are observed.
\end{abstract}

Phalloidin, one of the main toxic components of the green deathcap toadstool, Amanita phalloides, causes vacuolization of the liver parenchyma cells, so that the organ appears to be macroscopically swollen (1). In the isolated perfused rat liver, potassium efflux was observed a few minutes after application of the toxin (2). It has recently been reported that membrane preparations of in vivo poisoned rats as well as membrane preparations poisoned in vitro show a largely increased frequency of filamentous structures (3). Furthermore it could be shown (4) that ${ }^{3} \mathrm{H}$-labeled phallotoxin binds mainly to the fraction enriched with these filaments. Filament formation in membranes poisoned by phalloidin in vitro could largely be prevented when the membranes were preincubated with cytochalasin $\mathrm{B}$ for $10 \mathrm{~min}$ at $37^{\circ}(5)$.

Cytochalasin B has been reported to prevent the formation of contractile filaments in several cell types (6). Since an interaction of cytochalasin $\mathrm{B}$ with actin and actomyosin from muscle has already been reported (7, compare however ref. 20) and since actin-filaments have been found in several cell types, e.g., in blood platelets (8), in mammalian brain $(9,10)$, in Physarum polycephalum $(11,12)$ and furthermore since phalloidin induced filaments show globular subunits $(4,13)$, we supposed that the filaments in liver membrane preparations might possibly be actin. Therefore, we applied to the filaments 0.6 M KI which normally depolymerizes F-actin instantly. Furthermore, we tried a decoration with heavy meromyosin (HMM) as a direct proof. In addition, the effect of phalloidin on muscle actin was studied for comparison

Abbreviations: HMM, heavy meromyosin; Ph-actin, G-actin repolymerized by phalloidin in an ion free medium; $\mathrm{Ph}$-filaments, filaments induced by phalloidin in rat liver.

Request for reprints should be sent to Dr. Theodor Wieland, Max-Planck-Institut für Medizinische Forschung, D-69 Heidelberg, Jahnstr. 29 West Germany.

\section{MATERIALS AND METHODS}

Isolation of Cell Membrane Preparations. Two rats (body weights, about $250 \mathrm{~g}$ ), after a fast of $48 \mathrm{hr}$, were each poisoned by intravenous injection with $0.4 \mathrm{mg}$ of phalloidin in $1 \mathrm{ml}$ of $0.15 \mathrm{M} \mathrm{NaCl}$, and decapitated $10 \mathrm{~min}$ later. The livers were homogenized in $0.25 \mathrm{M}$ sucrose $/ 5 \mathrm{mM}$ Tris $\cdot \mathrm{HCl}$ at $\mathrm{pH} 8.0$ and fractionated by centrifugation after the modified method of Touster (5). The cell membrane fractions were washed two times and stored with either $0.25 \mathrm{mM}$ sucrose per $1 \mathrm{mM}$ Tris $\cdot \mathrm{HCl}$ at $\mathrm{pH} 7.4$, or with the Tris $\cdot \mathrm{HCl}$ buffer alone. The final protein concentration was $0.5 \mathrm{mg}$ in $1 \mathrm{ml}$ of homogenate.

Preparation of Actin. Actin (free from tropomyosin and troponin) was prepared as described by Dancker and Hoffmann (14), i.e., extraction of acetone powder from rabbit skeletal muscle with cold water and partial polymerization in $0.7 \mathrm{mM} \mathrm{MgCl}_{2}$. After ultracentrifugation, the actin pellets were covered with $1 \mathrm{ml}$ of $0.1 \mathrm{M} \mathrm{KCl}$. The F-actin pellets were depolymerized by suspending them for 3-4 hr in such an amount of $1 \mathrm{mM}$ Tris $\cdot \mathrm{HCl}$ at $\mathrm{pH} 7.4$ that the resulting concentration of G-actin was $1 \mathrm{mg} / \mathrm{ml}$. Only a few actin filaments could be seen in the electron microscope after this treatment. Repolymerization was performed to (i) F-actin in the G-F medium from Behnke (8) or (ii) Ph-actin by incubation with $80 \mu \mathrm{g}$ of phalloidin per $1 \mathrm{ml}$ of G-actin solution for $30 \mathrm{~min}$ at $20^{\circ}$ or $10 \mathrm{~min}$ at $37^{\circ}$. When the effect of cytochalasin $\mathrm{B}$ was tested, $1 \mathrm{ml}$ of G-actin solution was incubated with $400 \mu \mathrm{g}$ cytochalasin $\mathrm{B}$ in $20 \mu \mathrm{l}$ dimethylformamide for $10 \mathrm{~min}$ at $37^{\circ}$ before the addition of $80 \mu \mathrm{g}$ of phalloidin. For additional investigations, these stock solutions were diluted to $0.2-0.3 \mathrm{mg}$ of protein per $1 \mathrm{ml}$.

Assays with KI. Solid KI (100 mg) was added to $1 \mathrm{ml}$ of rat liver membrane homogenate or to $1 \mathrm{ml}$ of a solution containing F-or Ph-actin.

Preparation of Myosin and HMM. Myosin was prepared as described by Dancker and Hoffmann. HMM was obtained by the procedure of Eisenberg and Moos (15). The stock solution of $\mathrm{HMM}$ in $50 \mathrm{mM} \mathrm{KCl}$ and $10 \mathrm{mM}$ Tris $\cdot$ maleate $(3 \mathrm{mg}$ of protein per $1 \mathrm{ml}$ ) was diluted with nine volumes $\mathrm{G}-\mathrm{F}$ medium.

Protein Determination. The concentration of proteins was measured by the method of Lowry et al. (16).

Reaction of HMM with Liver Membrane Preparations and Actin-Filaments on the Grid. Small drops of samples, containing filaments, were applied to the grids and after the surplus 

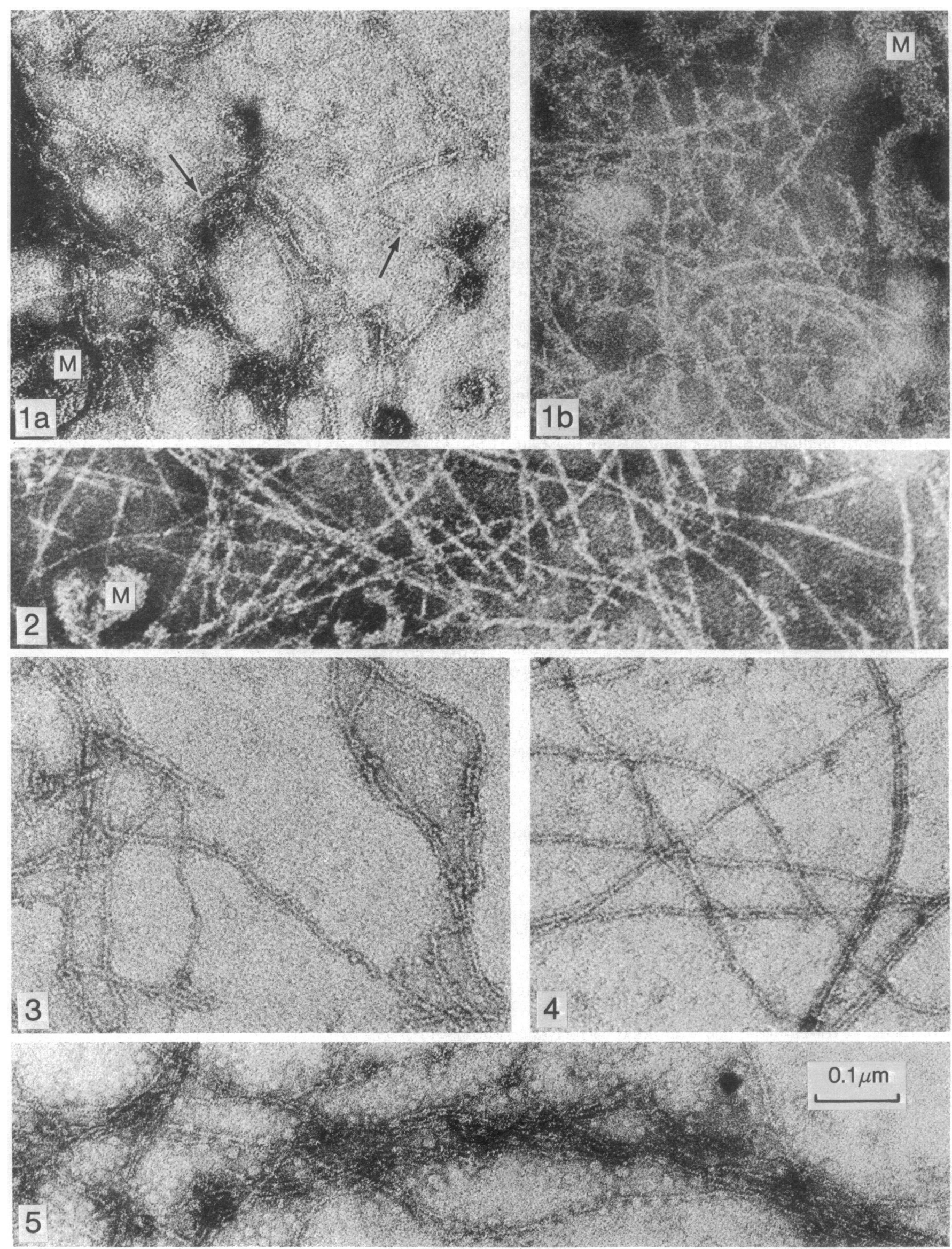

Figs. 1-5. Legend appears at top of next page. 
Figs. 1-5 (on preceding page). Magnification is $\times 160,000$ for all figures. (1) $\mathrm{Ph}$-filaments from liver membrane preparations from phalloidin poisoned rats, suspended in a sucrose medium, negatively stained with $1 \%$ uranylacetate $(1 a)$ or $1.5 \%$ phosphotungstic acid (1b). $M=$ membrane fragments. Arrows in $1 a$ point to recognizable double helical structure. (2) Ph-filaments from liver membrane preparations suspended in $1 \mathrm{mM}$ Tris. $\mathrm{HCl}$ buffer and treated with $0.6 \mathrm{M}$ KI for $16 \mathrm{hr}$ after negative staining with $1.5 \%$ phosphotungstic acid. $M=$ membrane fragment. (3) Ph-actin obtained from muscle G-actin by treatment with phalloidin in $1 \mathrm{mM}$ Tris. $\mathrm{HCl}$ and negatively stained with $1 \%$ uranylacetate. (4) F-actin from rabbit muscle negatively stained with $1 \%$ uranylacetate. (5) $\mathrm{Ph}$-actin as in 3 but treated with $0.6 \mathrm{M} \mathrm{KI}$ overnight and negatively stained with $1 \%$ uranylacetate.

amount of liquid was removed by a filter paper, a thin film of moisture was left. Then a droplet of HMM solution was added and allowed to react for 2-3 min. Before negative staining, the grids were washed briefly with G-F solution.

Electron Microscopy. Negative staining was done on Pioloform $\mathrm{F}$-carbon-coated grids either with $1.5 \%$ phosphotungstic acid ( $\mathrm{pH} 7.2$ ) to which $0.15 \%$ sucrose and $0.02 \%$ egg albumen had been added, or with $1 \%$ uranylacetate For electron micrographs we used a Siemens EM 101 equipped with an anticontamination device. A double condensor was used for illumination, and the operating voltage was $80 \mathrm{kV}$.

\section{RESULTS}

Effect of KI on phalloidin induced liver cell filaments (Ph-filaments)

Ph-filaments present in liver cell membrane preparations from poisoned animals are shown in Fig. $1 a$ (negatively stained with $1 \%$ uranylacetate) and $1 b$ (stained with $1.5 \%$ phosphotungstic acid). After staining with phosphotungstic acid, the beaded fine structure of the filaments is only faintly visible but staining with uranylacetate clearly demonstrates two helically wound strands composed of subunits (Fig. 1a, arrows) similar to muscle F-actin (compare with Fig. 4).

When the membrane preparations were treated with $0.6 \mathrm{M}$ $\mathrm{KI}$, most surprisingly, depolymerization of the filaments did not occur (Fig. 2) as expected for F-actin; on the contrary, the filaments displayed good structural preservation and even seemed to show a larger average length than preparations which had not been treated with KI.

\section{Effect of phalloidin on muscle actin}

Phalloidin has a polymerizing effect on G-actin. F-actin was depolymerized for $3-4 \mathrm{hr}$ in $1 \mathrm{mM}$ Tris $\cdot \mathrm{HCl}$ at $\mathrm{pH}$ 7.4. When examined in the electron microscope, only a few F-actin filaments were found. On addition of phalloidin $(80 \mu \mathrm{g} / \mathrm{mg}$ of protein), the G-actin was polymerized to filaments (Fig. 3) which closely resembled the muscle $\mathrm{F}$-actin obtained by polymerization of G-actin in $0.1 \mathrm{M} \mathrm{KCl}$ (Fig. 4) and differed from $\mathrm{Ph}$-filaments from rat liver only by their greater length. Likewise, the phalloidin induced actin filaments ( $\mathrm{Ph}$-actin) were resistant to 0.6 M KI (Fig. 5).

\section{Effect of cy tochalasin $B$ on the polymerization}

In accordance with our observation that cytochalasin B prevents the induction of $\mathrm{Ph}$-filaments in cell membrane preparations obtained from rat liver (5), a preincubation of the G-actin in $1 \mathrm{mM}$ Tris $\cdot \mathrm{HCl}$ with $1.0 \mathrm{mM}$ cytochalasin $\mathrm{B}$ for $10 \mathrm{~min}$ at $37^{\circ}$ yields a significantly smaller number of filamentous structures, either when polymerized in $0.1 \mathrm{M} \mathrm{KCl}$ or with phalloidin.

\section{Interaction of filaments with heavy meromyosin}

HMM was applied to all filament preparations on the grids for 2-3 min. Fig. 6 (p. 2806) shows muscle F-actin decorated with HMM. The usually described arrowhead structure is well rec- ognizable. Phalloidin did not prevent decoration. As shown in Fig. 7, Ph-actin also bound HMM and formed the typical arrowhead structure; however, the individual filaments seemed to be less densely decorated and some bare filaments were found. The $\mathrm{Ph}$-filaments from livers of poisoned rats could likewise be decorated with HMM (Fig. 8). Here, too, the density of HMM along the individual filaments seemed reduced in comparison to $\mathrm{F}$-actin and a number of bare strands were visible.

\section{DISCUSSION}

Microfilaments have been found in a wide variety of cell types but mostly within cells showing motility or contractility. Biochemical studies have revealed that these protein structures resemble muscle actin in physical, chemical, and structural properties. Most recently the occurrence of microfilaments was reported in epidermal cancer cells and was correlated with the motile invasive properties of these cells (17). The appearance of such structures in liver or other parenchyma cells has only occasionally been observed. Most of their cell actin exists probably in the depolymerized state. Presumably phalloidin renders it visible by irreversible polymerization. The present investigation has shown that muscle actin is polymerized by phalloidin to a $\mathrm{Ph}$-actin which is not depolymerized by $0.6 \mathrm{M} \mathrm{KI}$ and that this is also true for the phalloidin induced $\mathrm{Ph}$-filaments from rat liver cells. The inhibiting effect of cytochalasin $B$ agrees with the reports on prevention of the formation of contractile filaments (18). In the present study it could be clearly shown that it is the polymerization of G-actin to F-actin (by $0.1 \mathrm{M} \mathrm{KCl}$ ) as well as to Ph-actin (by phalloidin), which is blocked to a large extent by cytochalasin B; this is in agreement with our recent findings pertaining to liver membrane preparations which were preincubated with cytochalasin $B$ prior to in vitro poisoning (5). Since this drug exerts effects similar to that of phalloidin in a perfused rat liver preparation [vacuolization, swelling, $\mathrm{K}^{+}$-efflux (19)], one may suggest that for a cell to function normally, it is necessary that its actin pool can polymerize into filaments as well as depolymerize into smaller units and that inhibition of either of these processes might be fatal for the eell.

We wish to thank Mrs. Elizabeth Alexander-Jelinek and Mrs. Marianne Hoffmann for their invaluable technical assistance. We also thank Prof. Dr. E. Schnepf (Lehrstuhl für Zellenlehre, University of Heidelberg) and Prof. Dr. W. Franke (Deutsches Krebsforschungszentrum, Heidelberg) for their kind permission to use their electron microscopes.

1. Wieland, Th. \& Wieland, O. (1972) Microbial Toxins 8, 249-280.

2. Frimmer, M., Gries, J., Hegner, D. \& Schnorr, B. (1967) Naunyn-Schmiedebergs Arch. Pharmakol. Exp. Pathol. 258, 197-214.

3. Govindan, V. M., Faulstich, H., Wieland, Th., Agostini, B. \& Hasselbach, W. (1972) Naturwissenschaften 59, 521-522.

4. Govindan, V. M., Rohr, G., Wieland, Th. \& Agostini, W. (1973) Hoppe-Seyler's Z. Physiol. Chem. 354, 1159-1161.

5. Löw, I., Lengsfeld, A. \& Wieland, Th. (1974) Histochemistry 38, 253-258. 

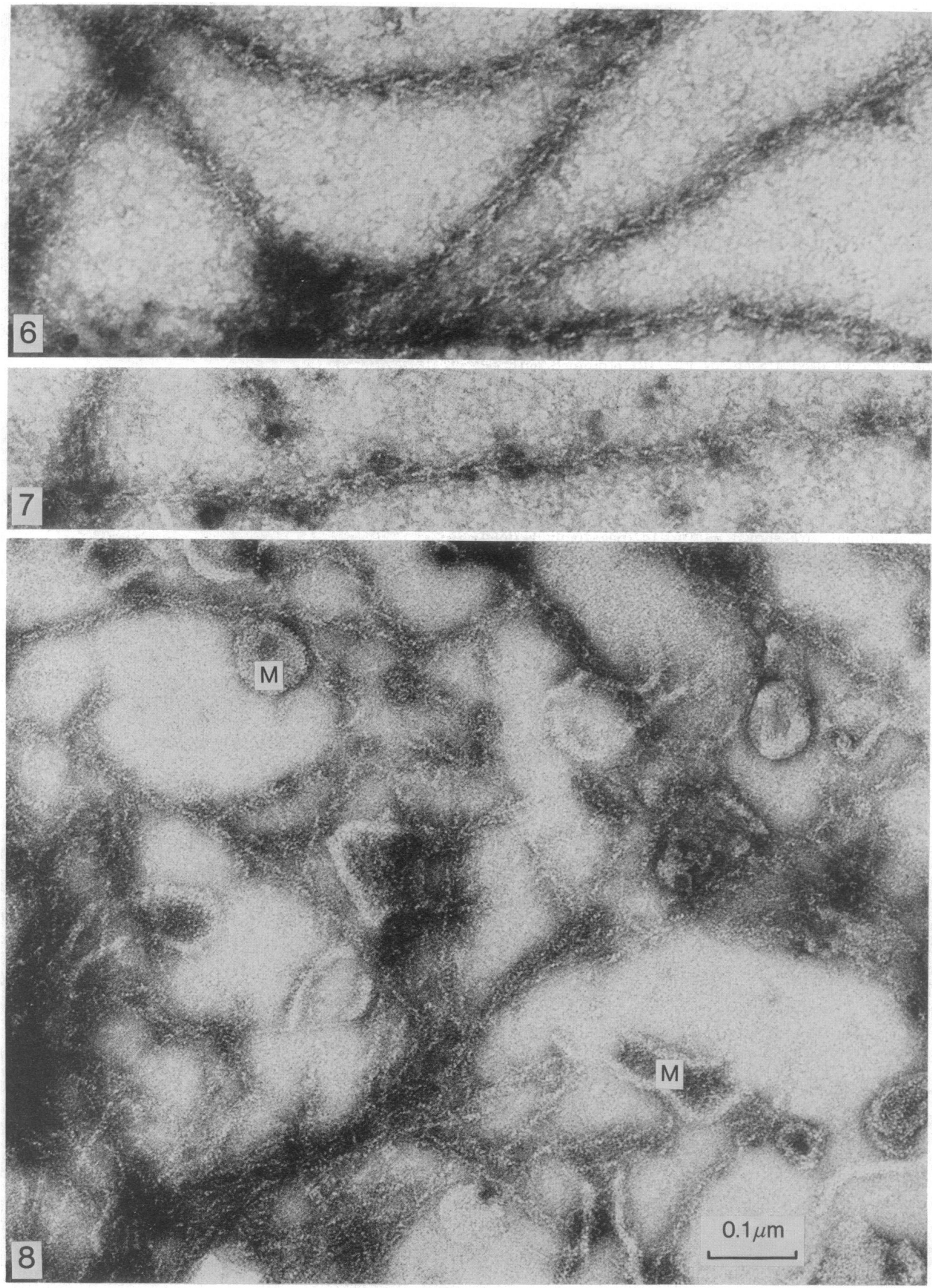

FIGS. 6-8 ( $\times 153,600$, negatively stained with uranyl acetate). (6) Muscle F-actin decorated with HMM. (7) Ph-actin decorated with HMM. (8) $\mathrm{Ph}$-filaments from a liver membrane preparation from phalloidin poisoned rats, suspended in a sucrose medium after decoration with HMM. $M=$ membrane fragment. 
6. Wessells, N. K., Spooner, B. S., Ash, J. F., Bradley, M. O., Luduena, M. A., Taylor, E. L., Wrenn, J. T. \& Yamada; K. M. (1971) Science 171, 135-143.

7. Spudich, J. A. \& Shin Lin (1972) Proc. Nat. Acad. Sci. USA $69,442-446$

8. Behnke, O., Kristensen, B. I. \& Nielson, L. E. (1971) J. Ultrastructure Research 37, 351-369.

9. Puszkin, S., Berl, S., Puszkin, E. \& Clarke, D. D. (1968) Science 161, 170-171.

10. Berl, S., Puszkin, S. \& Nicklas, W. J. (1973) Science 179, 441-446.

11. Nachmias, V. T. \& Huxley, H. E. (1972) J. Mol. Biol. 50, 83-90.

12. Wohlfarth-Bottermann, K. E. \& Stockem, W. (1972) Acta Protozoologica (Warschau) 11, 39-52,
13. Agostini, B. \& Govindan, V. M. (1973) Verh. Deut. Ges. Path. 57, 436.

14. Dancker, P. \& Hoffmann, M. (1973) Z. Naturforsch. 28c, 401-421.

15. Eisenberg, E. \& Moos, C. (1967) J. Biol. Chem. 242, 29452951.

16. Lowry, O. H., Rosebrough, N. J., Farr, A. L. \& Randall, R. J. (1951) J. Biol. Chem. 193, 265-275.

17. Malech, H. L. \& Lentz, Th. L. (1974) J. Cell Biol. 60, 473-482.

18. Allison, A. C. (1973) Ciba Found. Symp. 14, 144-145.

19. Jahn, W. (1973) Naunyn-Schmiedelbergs Arch. Pharmakol. Exp. Pathol. 278, 431-434.

20. Forer, A., Emmersen, J. \& Behnke, O. (1972) Science 175, 774-776. 